Check for updates

Cite this: RSC Adv., 2017, 7, 53362

Received 8th September 2017 Accepted 13th November 2017

DOI: $10.1039 / c 7 r a 10009 d$

rsc.li/rsc-advances

\section{Solar light assisted green synthesis of photoreduced graphene oxide for the high- efficiency adsorption of anionic dyes}

\author{
Yani Gong, ${ }^{\text {ab }}$ Chengbing Qin, (D) *ab Wenjun He, ${ }^{\text {ab }}$ Zhixing Qiao, ${ }^{\text {ab }}$ Guofeng Zhang, ${ }^{\text {ab }}$ \\ Ruiyun Chen, ${ }^{\mathrm{ab}}$ Yan Gao, ${ }^{\mathrm{ab}}$ Liantuan Xiao*ab and Suotang Jia ${ }^{\mathrm{ab}}$
}

\begin{abstract}
Graphene oxide (GO) with unique physical and chemical properties, such as high specific surface area, chemical stability and environmental friendliness, has been considered as an excellent adsorbent to remove organic dyes from polluted water. However, because of the electrostatic repulsion between the $\mathrm{GO}$ and anionic dyes, the adsorption capacity for anionic dyes is undesirable. Here photoreduced GO (PRGO) was prepared by solar light irradiation and used to investigate the adsorption capacity for anionic dyes. The obtained GO and PRGO were characterized by UV-visible absorption, Raman spectroscopy, atomic force microscopy (AFM), scanning electron microscopy (SEM), Fourier transform infrared (FTIR) and X-ray photoelectron spectroscopy (XPS). The adsorption kinetics and isotherms were evaluated through adsorption experiments of the anionic orange II (OII) dye adsorbed on GO or PRGO. The results revealed that the adsorption was an exothermic process and followed pseudo-second order kinetics. Four more typical anionic dyes, methyl orange (MO), Ponceau S (PS), Azo Rubine (AR), and Trypan Blue (TB), were also used to compare the adsorption capacities between GO and PRGO. It was demonstrated that the adsorption capacity of anionic dyes was significantly enhanced by PRGO, and the maximum enhancement was up to 8 fold. In conclusion, PRGO reduction by solar light irradiation in a green, convenient and cost effective manner, offers promise for the high-efficiency removal of anionic dyes in water treatment.
\end{abstract}

\section{Introduction}

Today, the shortage of fresh and clean water has become one of the most important challenges around the world; the serious water pollution arising from the rapid development of industry endangers human health., ${ }^{1,2}$ As an important source of water pollution, organic dyes mainly originate from the printing, textile, leather tanning and paper-making industries. ${ }^{3}$ Most of the dyes with heterocyclic or aromatic structures have been identified as toxic, mutagenic and even carcinogenic. ${ }^{4}$ Even more crucial, they are easily transported within the aqueous environments but hardly biodegradable. Various methods have been developed for the removal of organic dyes from wastewater, including membrane separation, ${ }^{5}$ ion exchange, ${ }^{6}$ chemical precipitation ${ }^{7}$ and so on. Of all the methods proposed, adsorption is the most commonly used because of its versatility, wide applicability and economic feasibility. ${ }^{8}$ With the

\footnotetext{
${ }^{a}$ State Key Laboratory of Quantum Optics and Quantum Optics Devices, Institute of Laser Spectroscopy, Shanxi University, Taiyuan, Shanxi 030006, China. E-mail: chbqin@sxu.edu.cn; xlt@sxu.edu.cn; Fax: +86 351 7113863; +86 351 7011682; Tel: +86351 7113863; +863517011682

${ }^{b}$ Collaborative Innovation Center of Extreme Optics, Shanxi University, Taiyuan, Shanxi 030006, China
}

development of nanomaterials, especially the discovery of graphene with unique chemical and physical properties, ${ }^{9,10}$ such as the large specific surface, chemical stability and environmental friendliness, graphene and its derivatives have emerged as a key materials for the removal of dyes. ${ }^{11-13}$ Among them, graphene oxide (GO) presents outstanding adsorption capacity for cationic dyes, arising from the $\pi-\pi$ interaction and electrostatic interaction between dyes and GO surface. ${ }^{14,15}$ However, the adsorption capacity of anionic dyes by GO is extremely low, due to the strong repulsion interaction between anionic dyes and electronegative GO.

In view of the electronegative nature of GO arising from the oxygen-containing functional groups on GO basal plane,${ }^{16}$ the reduction processes have been designed to improve the adsorption capacity of anionic dyes, by removing the functional groups and restoring the $\mathrm{sp}^{2} \pi$-conjugated network to enhance the $\pi-\pi$ interaction between the anionic dyes and reduced GO (RGO). In 2011, Ramesha and coworkers reduced GO using hydrazine hydrate and investigated the adsorption property of RGO on anionic dye of orange $\mathrm{G}(\mathrm{OG}) \cdot{ }^{17}$ The results showed that the RGO could act as a good adsorbent for anionic dyes, and the maximum adsorption capacity of OG was up to $5.98 \mathrm{mg} \mathrm{g}^{-1}$. Later, Sun group compared the adsorption capacities of $\mathrm{GO}$ and RGO on the anionic dye of acridine orange (MO), by in situ 
reducing GO with sodium hydrosulfite. ${ }^{18}$ They found that the maximum adsorption capacity of MO was improved by 2.35 folds after chemical reduction. Recently, Xiao et al. reported that the adsorption capacity of GO on anionic indigo carmine (IC) dye was enhanced by 3.63 folds, after reduction by Lcysteine. ${ }^{19}$ Hence, the RGO reduced by chemical reductants shows a promising alternative for the removal of anionic dyes from pollution water. While, the secondary pollution and energy waste during the chemical reduction still limits its further applications.

Here, we present an environmentally friendly and cost-free method to prepare photoreduced GO (PRGO) dispersion and investigate the adsorption capacities of GO and PRGO on anionic dyes. In the experiment, PRGO was synthesized by exposing GO dispersion to solar light irradiation in the sealed glasses with different duration time. ${ }^{20,21}$ Compared with other routes, this method is simple and easy for mass production, and it is not subject to experimental conditions. More importantly, this method avoids secondary pollution for the environment. The reduction degree was characterized by UV-visible absorption, Raman spectra, atomic force microscope (AFM), scanning electron microscope (SEM), Fourier transform infrared spectroscopy (FTIR), and X-ray photoelectron spectroscopy (XPS), respectively. The adsorption kinetics and isotherm of GO and PRGO on anionic Orange II (OII) dye have been measured and analyzed to explore the adsorption mechanism. The adsorption of OII dye on the PRGO materials was rapidly increased in the first 5 min and almost reaches the equilibrium in less than half an hour. Compared with GO, the adsorption rate was enhanced by 33 folds. The maximum adsorption capacity of OII was improved by 4 folds after solar reduction. Adsorption behavior on other four typical anionic dyes further evidence that the PRGO reduction by solar light irradiation is a green, convenient and cost-effective method without secondary pollution for the high-efficiency adsorption of anionic dyes.

\section{Experimental section}

\subsection{Materials}

The GO powder (the diameter of $0.5-5 \mu \mathrm{m}$ and thickness of 1-3 nm) was supplied by Nanjing XFNANO Materials Tech Co. Ltd. Orange II (OII), Methyl Orange (MO), Ponceau S (PS), Azo Rubine (AR), Trypan Blue (TB), and Ethylene Glycol (EG) were purchased from J\&K Scientific Ltd. All purchased dyes were used directly without any further purification. $0.22 \mu \mathrm{m}$ Millipore syringe filters were obtained from Tianjin Navigator Lab Instrument Co., Ltd. An Elix® Advantage system (Millipore Q, USA) was used to produce deionized water.

\subsection{Preparation of PRGO}

The GO powder was dissolved in deionized water $\left(2 \mathrm{mg} \mathrm{mL} \mathrm{mL}^{-1}\right)$ by ultrasonic dispersion to form a yellow-brown GO suspension, as shown in Fig. 1a. The as-prepared dispersion was stored in sealed transparent glass bottles. The reduction of GO was carried out by exposing $0.67 \mathrm{mg} \mathrm{mL}^{-1}$ dispersion to solar light with the duration time from $8 \mathrm{~h}$ to $72 \mathrm{~h}$. In order to maintain the same reduction condition, the experiments were performed in the same weather temperature $\left(30^{\circ} \mathrm{C}\right)$ and atmospheric environment (cloudless). Initial $\mathrm{pH}$ value of the dispersion was measured to be $5.0 \pm 0.3$ and no significant change was observed after photoreduction.

\subsection{Sample characterization}

GO and PRGO were characterized by a UV-visible absorption spectra on a Maya2000Pro Vis-NIR spectrometer (Ocean Optics), which was also used to measure the concentration of anionic dyes in the adsorption experiments. Raman spectra was carried out on a home-built scanning confocal system equipped with a $532 \mathrm{~nm}$ laser source and a long focus monochromator (Horbia Jobin Yvon, 1250M), which can be found in our previous works. ${ }^{2-24}$ The morphology of nanosheets was observed using SEM (SU8010, Hitachi, Japan). AFM (5000N, JEOL, Japan) was used to measure the height of GO and PRGO, respectively. FTIR used to characterize the chemical compositions of GO and PRGO was recorded on the Si substrate with a commercial Bruker FTIR spectrometer (Thermo Scientific Nicolet iS50). XPS analysis was conducted on an AXIS ULTRA DLD spectrometer (Thermo Kratos British) with $\mathrm{Al} \mathrm{K} \alpha$ irradiation as the exciting source $(300 \mathrm{~W})$.

\subsection{Dye adsorption experiments}

The adsorption capacities of GO and PRGO with different irradiation duration time were investigated by five anionic dyes, including OII, MO, PS, AR, and TB, whose concentrations were determined using UV-Vis spectrophotometer (Ocean Optics May2000Pro) based on their maximum absorbance wavelengths at 510, 462, 520, 515, and $598 \mathrm{~nm}$, respectively. Calibration plots of dye concentrations were established based on LambertBeer's Law. The adsorption experiments were performed by mixing $2 \mathrm{mg}$ GO or PRGO with a series of dye solutions with different initial concentrations at room temperature $\left(22^{\circ} \mathrm{C}\right)$ in the sealed bottles. After shaking at $80 \mathrm{rpm}$ in a shaker, the suspensions were withdrawn and filtered with $0.22 \mu \mathrm{m}$ Millipore syringe filters, and the residual concentrations of dyes were calculated according to UV-Vis absorption spectra. In the adsorption kinetics study, the dye aqueous with the volume of $3 \mathrm{~mL}$ and initial concentrations $C_{0}$ of $20 \mathrm{mg} \mathrm{L}^{-1}$ were mixed with $2 \mathrm{mg}$ GO or PRGO. After shaking, the concentration of residual dye solution $C_{t}$ were measured respectively at 5, 10, 15, $20,40,90,180,330,450,570,750$, and $1440 \mathrm{~min}(24 \mathrm{~h})$ from the beginning. The adsorption capacities $q_{t}$ for dyes adsorbed onto GO or PRGO were determined according the following equation:

$$
q_{t}=\frac{\left(C_{0}-C_{t}\right) \times V}{m}
$$

where $V$ is the volume of the solution (L) and $m$ is the mass of GO or PRGO $(\mathrm{g})$, respectively. In the equilibrium isotherm experiments, $3 \mathrm{~mL}$ dyes solutions with initial concentrations $C_{0}$ of $6.7,13,20,26.7,33,40,46.7,53,60$, and $67 \mathrm{mg} \mathrm{L}^{-1}$ were mixed with $2 \mathrm{mg} \mathrm{GO}$ or PRGO at room temperature. The amount of dyes adsorption at equilibrium $q_{\mathrm{e}}\left(\mathrm{mg} \mathrm{g}^{-1}\right)$ can be obtained by the equation: 
(a)

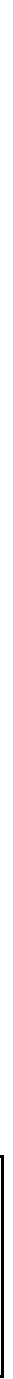

Fig. 1 (a) Photographic images of GO (left first) and PRGO with irradiation duration time of 8, 16, 24, 32, 40, 48, 56, 64, and 72 h, respectively. (b) and (c) are absorption and Raman spectra of GO and PRGO with irradiation duration time of $72 \mathrm{~h}$, respectively.

$$
q_{\mathrm{e}}=\frac{\left(C_{0}-C_{\mathrm{e}}\right) \times V}{m}
$$

where $C_{\mathrm{e}}$ is the concentrations of residual dyes solutions after shaking for $24 \mathrm{~h}$.

\subsection{Desorption and recycling test}

The adsorption stability of PRGO was investigated by recycling the material through dyes adsorption-desorption experiments. In a typical experiment, $3 \mathrm{~mL}$ dyes with concentration of $60 \mathrm{mg} \mathrm{\textrm {L } ^ { - 1 }}$ was mixed with $2 \mathrm{mg}$ PRGO and shaking for $24 \mathrm{~h}$ at room temperature. The adsorbents were subsequently removed from the solutions by filtration and washed with EG and deionized water. The residual dyes were measured to calculate the adsorption capacities. The EG washed GO or PRGO was then dissolved with deionized water again and used in the second cycle adsorption experiment. This process was repeated in four cycles for OII dye.

\section{Results and discussion}

\subsection{Photoreduction and characterization}

The reduction of GO was carried out by exposing its suspension hold in sealed transparent glass bottles to solar light. Fig. 1a presents the photograph of GO suspensions before and after exposition with duration time from 8 to $72 \mathrm{~h}$. Clearly, the color of the suspensions changed from yellow-brown to deep black gradually as the increasing of exposition time. Conventional absorption spectroscopy was performed on the initial (black line) and the last (72 h, blue line) suspensions, as shown in Fig. 1b. The PRGO can be significantly distinguished from the GO spectrum by an increasing of absorption in the range of 400-1000 nm, ${ }^{25}$ in accordance with their color change. The increased absorption corresponds to the removal of oxygencontaining functional groups and the restoration of the $\operatorname{sp}^{2} \pi$ conjugated network in the PRGO nanosheets. Fig. 1c displays the Raman spectra from suspensions before (black line) and after (blue line) solar irradiation with $72 \mathrm{~h}$, respectively. The two prominent peaks can be determined in both materials, which are corresponding to D and $\mathrm{G}$ band, respectively. The $\mathrm{G}$ band is usually represented the first order scattering of the $\mathrm{E}_{2 \mathrm{~g}}$ phonon of $\mathrm{sp}^{2}$ carbon, while the $\mathrm{D}$ band is associated with structural defects and disorders. ${ }^{26}$ The D and G bands are fitting by Gauss function with the center values of $1320,1555 \mathrm{~cm}^{-1}$ for GO, and 1318 and $1553 \mathrm{~cm}^{-1}$ for PRGO, respectively. A slight redshift can be explained by a graphitization of the sample, as reported by the previous literature. ${ }^{25,27}$ Furthermore, the intensity ratio of $D$ to $\mathrm{G}$ band $\left(I_{\mathrm{D}} / I_{\mathrm{G}}\right)$ can be used to denote the disorder degree and averaged crystal size of the $\mathrm{sp}^{2}$ network. ${ }^{28,29}$ The increased $I_{\mathrm{D}} / I_{\mathrm{G}}$ ratio from 1.17 for GO to 1.76 for PRGO indicates the decreased sizes but the increased numbers of $\mathrm{sp}^{2}$ frameworks. ${ }^{30}$

The chemical compositions of GO before and after solar light irradiation were investigated using FTIR measurements. As shown in Fig. 2a, the band between 3600 and $2800 \mathrm{~cm}^{-1}$ is attributed to the $\mathrm{O}-\mathrm{H}$ stretching vibration arising from hydroxyl groups, the bands at 1730,1620 , and $1045 \mathrm{~cm}^{-1}$ can be described as the stretching modes of $\mathrm{C}=\mathrm{O}, \mathrm{C}=\mathrm{C}$, and $\mathrm{C}-\mathrm{O}$ groups, and the peaks located at 1410 and $1195 \mathrm{~cm}^{-1}$ are assigned to the bending vibration of $\mathrm{C}-\mathrm{OH}$ groups as well as $\mathrm{C}-\mathrm{O}-\mathrm{C}$ asymmetric stretching vibration of epoxy group, respectively. ${ }^{31,32}$ The decrease or even disappear of hydroxyl and epoxy groups, as well as the increases of carboxyl strongly indicates the reduction during light irradiation. The position of $\mathrm{C}=\mathrm{C}$ peak shifts from $1620 \mathrm{~cm}^{-1}$ to $1590 \mathrm{~cm}^{-1}$, possibly because of the restoration of $\mathrm{sp}^{2}$ structures. Here, we also used XPS to quantify the degree of reduction. The $\mathrm{C} / \mathrm{O}$ ratio can be 
(a)

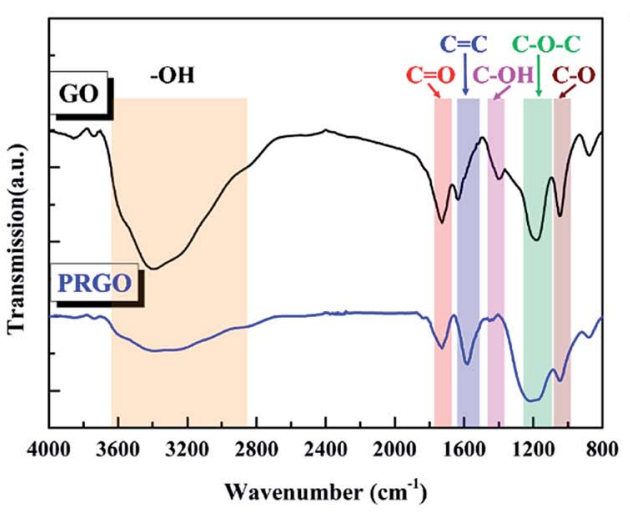

(c)

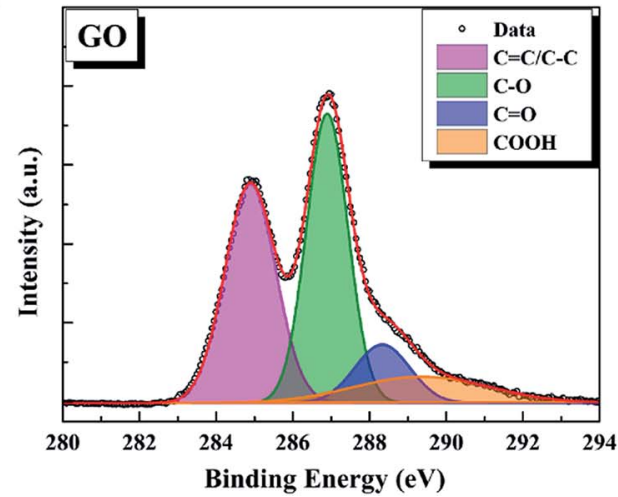

(b)

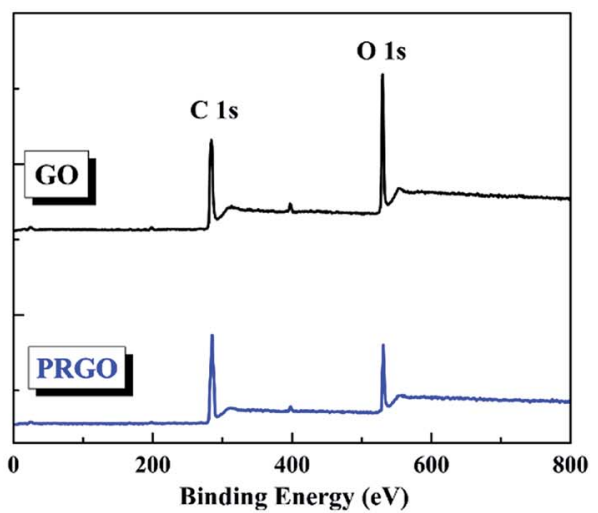

(d)

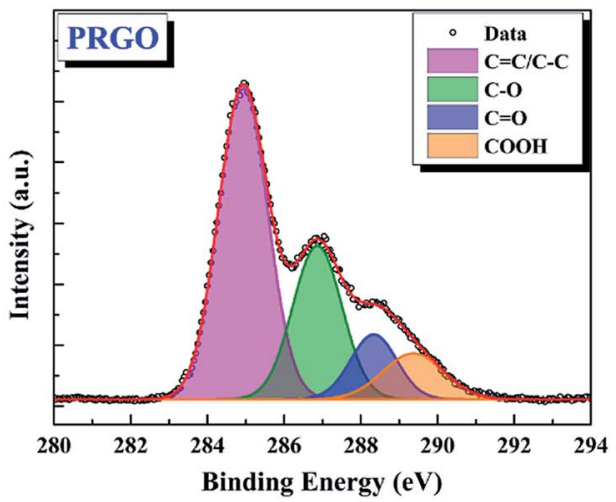

Fig. 2 (a) FTIR spectra of GO and PRGO with irradiation duration of $72 \mathrm{~h}$, respectively. (b) -(d) are XPS survey spectra and curve fit of C 1s spectra of $\mathrm{GO}$ and PRGO with irradiation duration of $72 \mathrm{~h}$, respectively.

calculated from the atomic percentages obtained from the survey XPS spectra, ${ }^{29}$ as shown in Fig. $2 \mathrm{~b}$. The ratio of GO sample before and after solar light irradiation increases from 2.54 to 6.19 , revealing the removal of oxygen-containing functional groups from $\mathrm{GO}$ basal plane. Fig. $2 \mathrm{c}$ and d present the $\mathrm{C}$ 1s deconvolution spectra of GO before and after irradiation, respectively. The spectra can be curve-fitted into four peak components with binding energy at about 284.9, 286.9, 288.4, and $289.4 \mathrm{eV}$, corresponding to the $\mathrm{C}=\mathrm{C} / \mathrm{C}-\mathrm{C}, \mathrm{C}-\mathrm{O}$ (hydroxyl and epoxy), $\mathrm{C}=\mathrm{O}$ (carbonyl), and $\mathrm{O}=\mathrm{C}-\mathrm{O}$ (carboxyl) species, respectively ${ }^{33}$ The increase of $\mathrm{C}=\mathrm{C}$ peak and the decrease of $\mathrm{C}-\mathrm{O}$ peak hint that the conjugation $\mathrm{sp}^{2}$ structures were restored and the epoxy and alkoxy groups on the GO surface were removed, respectively. Nevertheless, the carbonyl and carboxyl at the sheet edges have little change, which is similar to the reduction by chemical agents. ${ }^{34}$

The surface morphology of GO before and after solar irradiation were analyzed by AFM and SEM. From AFM images (Fig. 3a and b), it can be found that GO nanosheets are exfoliated into monolayer with the lateral size in the region of $0.5-5 \mu \mathrm{m}$ and the height of $\sim 1.3 \mathrm{~nm}$. After solar irradiation, the nanosheets are still monolayer with the height of $\sim 0.7 \mathrm{~nm}$, indicating the effective removal of functional groups on the basal plane of GO. Fig. 3c and d present the SEM images of GO and PRGO, respectively. As reported in the previous works, ${ }^{18} \mathrm{GO}$ exhibits ordered structures, while PRGO shows exfoliated nanosheets and folding nature. Because of abundant hydrophilic functional groups on the basal plane of $\mathrm{GO}$ (such as -OH), many interlayered hydrogen bonds will be formed during filtration and evaporation progresses, and lead to the formation of ordered GO nanosheets. After solar irradiation, the PRGO becomes less hydrophilic due to the loss of functional groups. The decreased interlayer interaction results in less compact and more crumpled, as well as the high surface area for effective adsorption.

The reduction of GO by solar light irradiation can be explained by photochemical effect. The solar light has a broad spectral distribution from ultraviolet to infrared ( $\sim 4.27-$ $1.55 \mathrm{eV}$ ). As proved by Ida and Antonietti, ${ }^{35,36}$ the ultraviolet irradiation is very effective in reducing GO through lightgenerated electron-hole pairs, which can be immediately formed during irradiation. Then the generated electron-hole pairs move to the functional groups on the GO basal plane, and result in the remove of hydroxyl groups $(-\mathrm{OH})$. While a certain number of carbonyl $(\mathrm{C}=\mathrm{O})$ and carboxyl $(\mathrm{O}=\mathrm{C}-\mathrm{O})$ groups still remain, as evidenced by FTIR and XPS spectra shown in Fig. 2 . The non-uniform reduction results on functional groups can be attributed to their quite different bonding energies. Theoretical calculations have shown that the binding energy of hydroxyl group adsorbed onto graphene plane is estimated to be $1.5 \mathrm{eV}$, while that of $\mathrm{C}-\mathrm{C}$ bond in carbonyl and carboxyl exceeds $5.8 \mathrm{eV}^{37,38}$ As a consequent, only the hydroxyl group was 
(a)

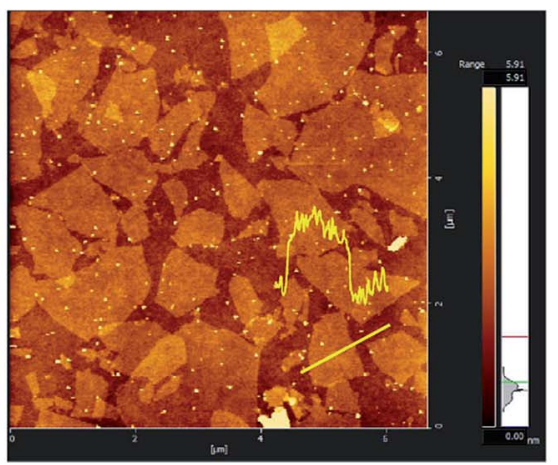

(c)

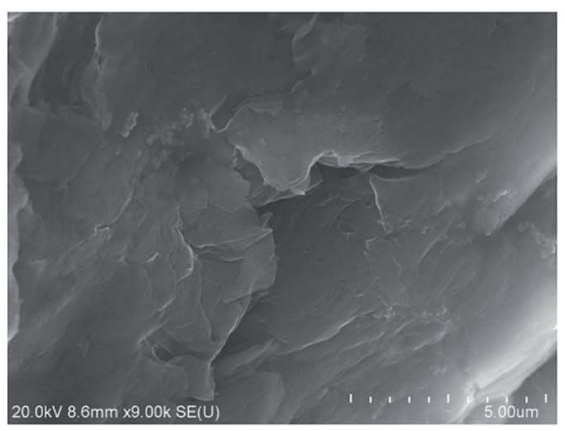

(b)

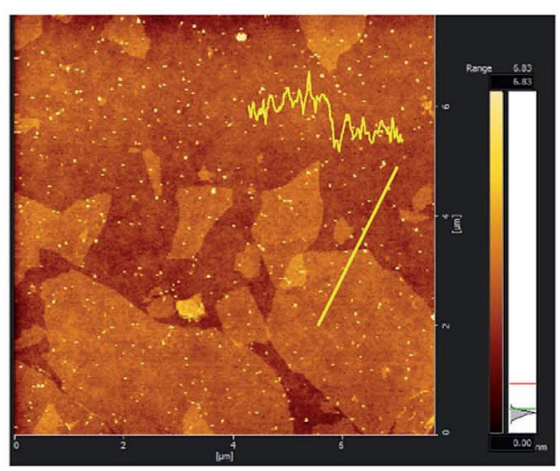

(d)

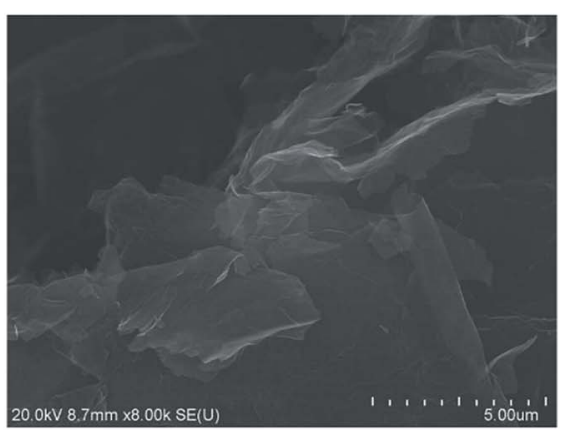

Fig. 3 (a) and (b) are AFM images of GO and PROG, respectively. (c) and (d) are SEM images of GO and PROG, respectively.

dissociated efficiently. Furthermore, on the contrast to the solar reduction by a convex lens ${ }^{20}$ which resulted in the rapid heating and temperature increasing, the reduction under this experiment is mild without significant temperature change. Thus, photothermal effect can be ignore.

\subsection{Adsorption kinetics}

In order to understand the mechanism of the adsorption process and evaluate the adsorption capacity, the adsorption kinetics experiments were performed by measuring the timedependent dye adsorption behaviors. Given the similar adsorption kinetics for the anionic dyes used in our experiments, here we only display the experimental results of OII dye. Fig. 4a presents the adsorption capacity of OII varying as the equilibrium time in the range of $5 \mathrm{~min}$ to $24 \mathrm{~h}$ for $\mathrm{GO}$ and PRGO, respectively. As expected, the adsorption capacity of OII on PRGO are much higher than that of GO materials. Here, PRGO-1, PRGO-2, and PRGO-3 denote the GO exposing to the solar light with the duration time of 24,48 , and $72 \mathrm{~h}$, respectively. Furthermore, the adsorption of OII dye on all PRGO materials is rapidly increased in the first $5 \mathrm{~min}$ and almost reaches the equilibrium in less than half an hour. However, the adsorption on GO is relatively slow and reaches the equilibrium at about $10 \mathrm{~h}$. The high adsorption capacity as well as fast adsorption rate can be attributed to the availability of a large number of adsorption sites on PRGO surface, resulting from the restoration of small but abundant $\mathrm{sp}^{2} \pi$-conjugated structures. These sites make the aromatic dyes contacting immediately with the surface of PRGO with the aid of strong $\pi-\pi$ interaction, while the GO surface with many functional groups slows down the adsorption rate due to the steric effect and less $\mathrm{sp}^{2}$ structures.

To get insight into the adsorption processes and determine the kinetic parameters, the experimental data are fitted by three different kinetic models: (1) the pseudo-first order model, (2) pseudo-second order model and (3) intraparticle diffusion model, respectively.

The pseudo-first order model describes the adsorption that the change of adsorption rate over time is directly proportional to the difference between equilibrium and current adsorption capacity. ${ }^{39}$ Its linear form can be expressed as the following:

$$
\ln \left(q_{\mathrm{e}}-q_{t}\right)=\ln \left(q_{\mathrm{e}}\right)-k_{1} t
$$

where $q_{t}$ and $q_{\mathrm{e}}$ are the adsorption capacities in $\mathrm{mg} \mathrm{g}^{-1}$ at equilibrium and at time $t$ in min, and $k_{1}$ is the rate constant of adsorption in $\min ^{-1}$, respectively. The $q_{\mathrm{e}}$ and $k_{1}$ can be determined from the slopes and intercepts of $\ln \left(q_{\mathrm{e}}-q_{\mathrm{t}}\right)$ against the $t$ plots, as shown in Fig. $4 \mathrm{~b}$. The resulted kinetic parameters for GO and PRGO with different reduction degree are presented in Table 1. The results show that the linear correlation coefficients $\left(R^{2}\right)$ are among 0.537 to 0.686 , indicating the pseudo-first order model cannot be used to describe the adsorption process.

On the other hand, the pseudo-second order model is generally used to depict the chemisorption process with a ratelimiting step, ${ }^{39}$ which can be represented as equation: 
(a)

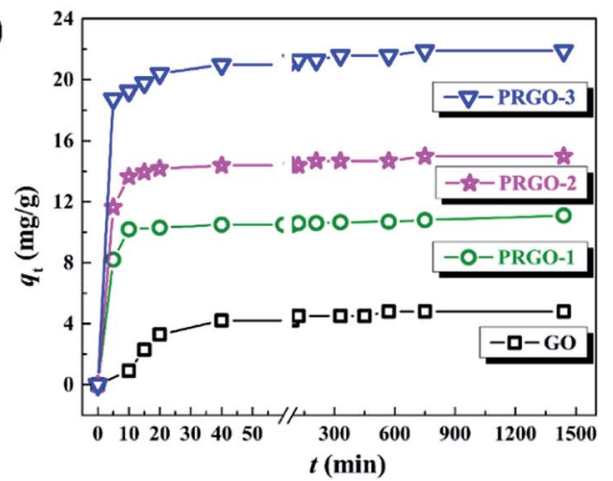

(c)

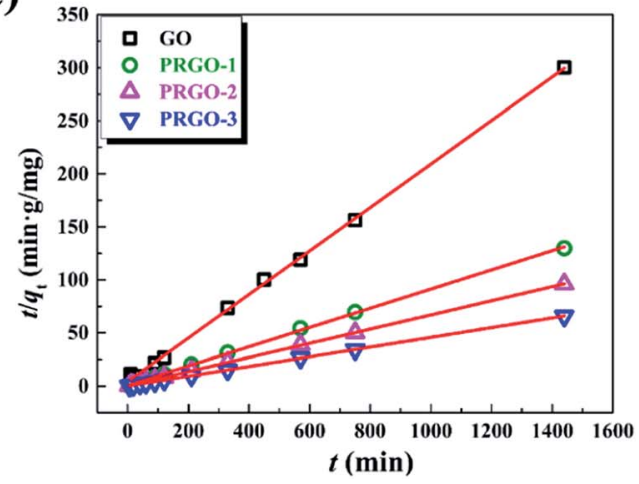

(b)

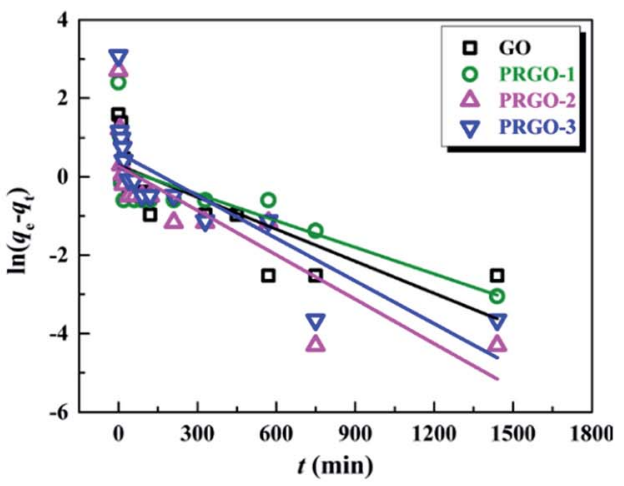

(d)

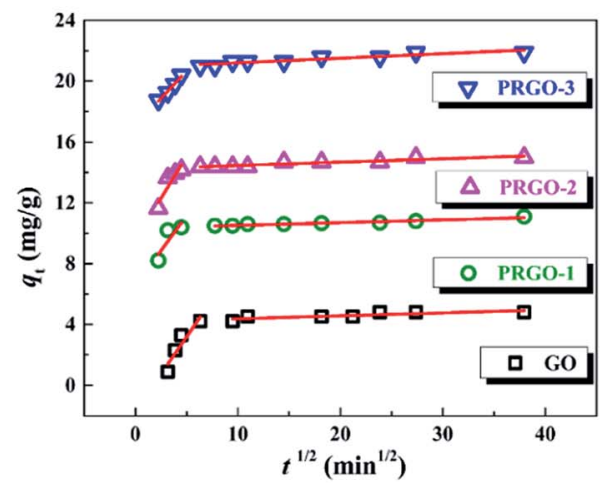

Fig. 4 (a) Adsorption kinetics of OII on GO and PRGO-1, 2, 3 with irradiation duration of 24, 48, and 72 h, respectively. (b)-(d) are the plots of pseudo-first order model, pseudo-second order and intraparticle diffusion models for the Oll adsorption on GO and PRGO, respectively.

Table 1 Parameters of pseudo-first order and pseudo-second order kinetic models

\begin{tabular}{|c|c|c|c|c|c|}
\hline \multirow[t]{2}{*}{ Pseudo-first order } & $q_{\mathrm{e}}\left(\mathrm{mg} \mathrm{g}^{-1}\right)$ & 1.35 & 1.64 & 1.35 & 1.91 \\
\hline & $k_{1}\left(\min ^{-1}\right)$ & $3.0 \times 10^{-3}$ & $4.0 \times 10^{-3}$ & $4.0 \times 10^{-3}$ & $4.0 \times 10^{-3}$ \\
\hline \multirow[t]{3}{*}{ Pseudo-second order } & $q_{\mathrm{e}}\left(\mathrm{mg} \mathrm{g}^{-1}\right)$ & 4.88 & 11.1 & 15.0 & 21.9 \\
\hline & $V_{0}\left(\mathrm{mg}\left(\mathrm{g}^{-1} \min ^{-1}\right)\right)$ & 0.237 & 1.45 & 3.98 & 7.87 \\
\hline & $k_{2}\left(\mathrm{~g}\left(\mathrm{mg}^{-1} \mathrm{~min}^{-1}\right)\right)$ & $1.0 \times 10^{-2}$ & $1.2 \times 10^{-2}$ & $1.8 \times 10^{-2}$ & $1.6 \times 10^{-2}$ \\
\hline
\end{tabular}

$$
\frac{t}{q_{t}}=\frac{t}{q_{\mathrm{e}}}+\frac{1}{k_{2} q_{\mathrm{e}}{ }^{2}}
$$

similarly, $q_{\mathrm{e}}$ is the adsorption capacity at equilibrium and $q_{t}$ is the adsorption amount of dyes at time $t$, respectively. The $k_{2}$ parameter in $\mathrm{g}\left(\mathrm{mg}^{-1} \mathrm{~min}^{-1}\right)$ denotes the rate constant of the pseudo-second order kinetic model. Specifically, the value $V_{0}$ represents the adsorption rate at initial time, ${ }^{34}$ where

$$
V_{0}=k_{2} q^{2}
$$

All the parameters can be determined by linearly fitting the plots of $t / q_{t}$ against time $t$, and the results are presented in Table 1. The large linear correlation coefficients, $R^{2}>0.999$, suggest that the OII absorbed on GO and PRGO follows the pseudo-second order kinetic model. More importantly, the equilibrium adsorption capacity of PRGO-3 with solar light exposing duration of $72 \mathrm{~h}$ is 4.5 -fold higher than that of GO suspensions. And the initial adsorption rate of PRGO-3 is even enhanced by 33 folds, in accord with the experimental results shown in Fig. 4a.

The intraparticle diffusion is also used to reveal the possible diffusion mechanism, which describes the successive processes of dyes diffusion through the boundary layer, intraparticle diffusion and adsorption on the surfaces of GO and PRGO. ${ }^{40}$ The equation could be expressed as the following form:

$$
q_{t}=k_{\mathrm{p} i} t^{1 / 2}+C_{i}
$$

where $k_{\mathrm{p} i}$ is the intraparticle diffusion rate constant of stage $i$ in $\mathrm{mg}\left(\mathrm{g}^{-1} \mathrm{~min}^{-1 / 2}\right)$, and $C_{i}$ in $\mathrm{mg} \mathrm{g}^{-1}$ is the intercept of stage $i$, which gives the information about the thickness of the boundary layer. That is the larger the $C_{i}$, the greater the boundary-layer effect. ${ }^{40}$ Fig. $4 \mathrm{~d}$ presents the plots of $q_{t} v s . t^{1 / 2}$ and their fitting lines, the calculated parameters have been 
presented in Table 2. Even though the correlation coefficients are pretty low, two distinguished stages still can be determined. The first sharp stage can be attributed to external diffusion that is the diffusion of dyes through the solution to the bare or restored $\mathrm{sp}^{2} \pi$-conjugated sites on the surface of monolayer nanosheets. The second stage is intra-particle diffusion, which describes the diffusion of dyes to the small $\mathrm{sp}^{2}$ structures surrounding by oxygen-containing functional groups. As presented in Table 2, the diffusion rates of $k_{\mathrm{p} 1}$ for GO and PRGO are much higher that $k_{\mathrm{p} 2}$, while the $C_{1}$ are slightly lower than $C_{2}$. This phenomenon indicates that in the beginning a large amount of adsorbed sites are availability on the GO and PRGO surface, resulting in the high adsorption rate. This results are also coincide with the rapidly increased adsorption in the first 5 min, as shown in Fig. 4a. In the second step, the adsorption rate was controlled by the rate of the dyes transported from the bare-sp ${ }^{2}$ sites to the $\mathrm{sp}^{2}$ sites surrounding by oxygen-containing functional groups. The steric effect of functional groups and electrostatic repulsion between functional groups and anionic dyes results in the extremely slow adsorption rates. Furthermore, either in the first stage or in the second stage, the $C_{i}$ values increases with the increasing of duration time under solar light, which can be attributed to the increasing of $\mathrm{sp}^{2}$ $\pi$-conjugated structures during photoreduction process.

\subsection{Adsorption isotherm}

The adsorption isotherm here describes the adsorption capacity of OII dye adsorbed per unit weight of GO or PRGO materials $\left(q_{\mathrm{e}}, \mathrm{mg} \mathrm{g}^{-1}\right)$, and also the relationship between the adsorption capacity and the dyes concentrations at equilibrium condition $\left(C_{\mathrm{e}}, \mathrm{mg} \mathrm{L}^{-1}\right)$. Adsorption isotherm can provide in-depth information about adsorption mechanisms, surface properties and affinity of an adsorbent towards an adsorbate. The adsorption

Table 2 Parameters of interparticle diffusion kinetic model

\begin{tabular}{|c|c|c|c|c|c|}
\hline & Parameters & GO & PRGO-1 & PRGO-2 & PRGO-3 \\
\hline \multirow[t]{2}{*}{ First stage } & $k_{\mathrm{p} 1}\left(\mathrm{mg}\left(\mathrm{g}^{-1} \min ^{-1 / 2}\right)\right)$ & $9.8 \times 10^{-1}$ & $9.3 \times 10^{-1}$ & $1.1 \times 10^{0}$ & $1.0 \times 10^{-1}$ \\
\hline & $C_{1}\left(\mathrm{mg} \mathrm{g}^{-1}\right)$ & 1.70 & 6.54 & 9.53 & 17.0 \\
\hline \multirow[t]{3}{*}{ Second stage } & $k_{\mathrm{p} 2}\left(\mathrm{mg}\left(\mathrm{g}^{-1} \min ^{-1 / 2}\right)\right)$ & $1.9 \times 10^{-2}$ & $1.8 \times 10^{-2}$ & $2.2 \times 10^{-2}$ & $3.0 \times 10^{-2}$ \\
\hline & $C_{2}\left(\mathrm{mg} \mathrm{g}^{-1}\right)$ & 4.17 & 10.3 & 14.2 & 20.9 \\
\hline & $R^{2}$ & 0.636 & 0.930 & 0.848 & 0.852 \\
\hline
\end{tabular}

(a)

(c)
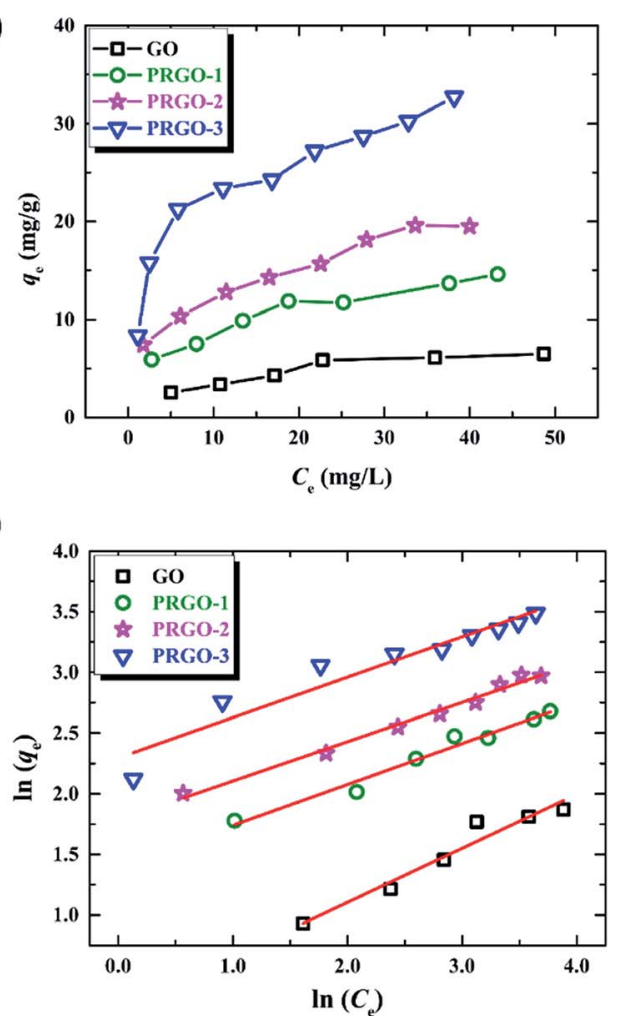

(b)

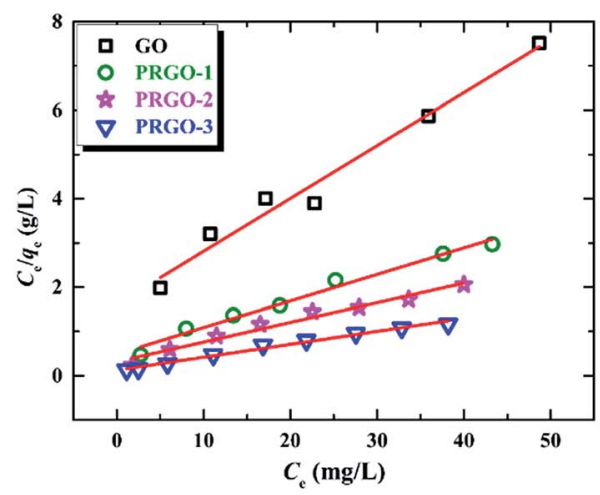

(d)

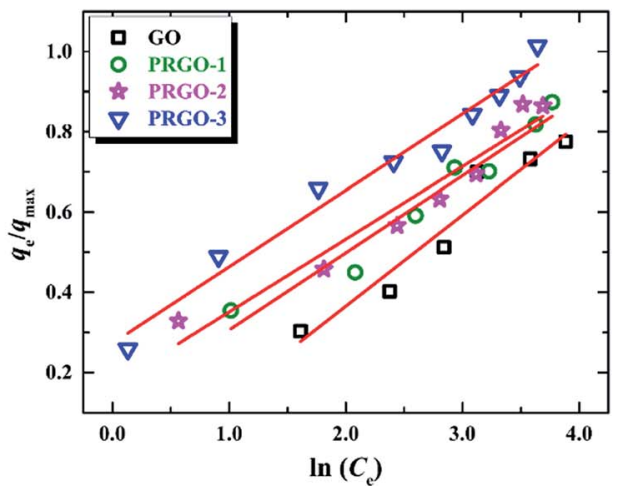

Fig. 5 (a) Adsorption isotherms of Oll on GO and PRGO-1, 2, 3, respectively. (b)-(d) are the plots of Langmuir, Freundlich and Temkin isotherm models for the Oll adsorption on GO and PRGO, respectively. 
of OII dye on GO or PRGO with different initial concentrations have been investigated. The adsorption capacities as well as the equilibrium concentrations have been determined after shaking the mixed aqueous with $24 \mathrm{~h}$ under room temperature $\left(22{ }^{\circ} \mathrm{C}\right)$, as shown in Fig. 5a. Apparently, PRGO displays much larger adsorption capacity than GO. Furthermore, as the increasing of reduction degree, the capacity was distinctly improved. On the other hand, as the increasing of the equilibrium concentrations (associating with the increasing of initial concentrations), the adsorption capacities tend to saturation. To determine the maximum adsorption capacity and the mechanistic parameters, three most commonly used models are adopted to analyze the experimental data: Langmuir, Freundlich and Temkin isotherm models.

The Langmuir model depicts the monolayer adsorption process on a uniform surface with no interaction among the adsorption molecules (dyes). ${ }^{39}$ It can be expressed as equation as following:

$$
\frac{C_{\mathrm{e}}}{q_{\mathrm{e}}}=\frac{C_{\mathrm{e}}}{q_{\max }}+\frac{1}{q_{\max }} \frac{1}{K_{\mathrm{L}}}
$$

where $q_{\text {max }}$ is the maximum adsorption capacity in $\mathrm{mg} \mathrm{g}^{-1}$, corresponding to the complete monolayer coverage, $K_{\mathrm{L}}$ is the Langmuir constant in $\mathrm{L} \mathrm{mg}^{-1}$, related to the affinity of the binding sites and energy of adsorption. All the parameters of Langmuir model are presented in Table 3, which are determined by linearly fitting the plots of $C_{\mathrm{e}} / q_{\mathrm{e}}$ against $C_{\mathrm{e}}$, as shown in Fig. 5 b. The correlation coefficients, $R^{2}$, in the range of 0.969 to 0.985 indicate that the experimental data are in good agreement with the Langmuir model. The maximum adsorption capacity for PRGO-3 is $32.2 \mathrm{mg} \mathrm{g}^{-1}$, which is about 4-fold larger than GO with that of $8.36 \mathrm{mg} \mathrm{g}^{-1}$. The increased $K_{\mathrm{L}}$ values hint that the deeper the reduction, the stronger the dye adsorbed on materials. Another fundamental characteristic of Langmuir model is the separation factor $R_{\mathrm{L}}$, given by:

$$
R_{\mathrm{L}}=\frac{1}{1+K_{\mathrm{L}} C_{0}}
$$

where $C_{0}$ is the highest initial dye concentration used in the study $\left(67 \mathrm{mg} \mathrm{L}{ }^{-1}\right) . R_{\mathrm{L}}$ represents the isotherm to be either irreversible $\left(R_{\mathrm{L}}=0\right)$, favorable $\left(0<R_{\mathrm{L}}<1\right)$, linear $\left(R_{\mathrm{L}}=1\right)$, or unfavorable $\left(R_{\mathrm{L}}>1\right){ }^{40}$ The small $R_{\mathrm{L}}$ values in the Table 3 indicate that the adsorption of OII dye on both GO and PRGO are the favorable processes. The smallest $R_{\mathrm{L}}$ for PRGO-3 strongly suggests that increasing the initial concentration will improve the adsorption.

On the contrast to the monolayer adsorption of Langmuir model, the Freundlich model is based on the assumption of multilayer adsorption, ${ }^{41}$ described as:

$$
\ln q_{\mathrm{e}}=\frac{1}{n} \ln C_{\mathrm{e}}+\ln K_{\mathrm{F}}
$$

here $K_{\mathrm{F}}$ is an indicator of the adsorption capacity, and $1 / n$ is an empirical heterogeneity factor, providing an indication of the deviation from linearity of adsorption. $1 / n$ quantifies the favorability of adsorption and the degree of heterogeneity of the surface. When $1 / n<1$, it suggests favorable adsorption process and also a normal Langmuir isotherm. ${ }^{34}$ The corresponding values have been displayed in Table 3 by fitting the experimental data, as shown in Fig. $5 c$. The values of $1 / n$ lower than 1 further evidence the adsorption of OII on GO and PRGO are favorable Langmuir adsorption processes.

The Temkin is also used to analyze the data to uncover thermodynamic information, which assumes that the heat of adsorption of dyes in the layer decreases linearly with coverage, ${ }^{42}$ represented by:

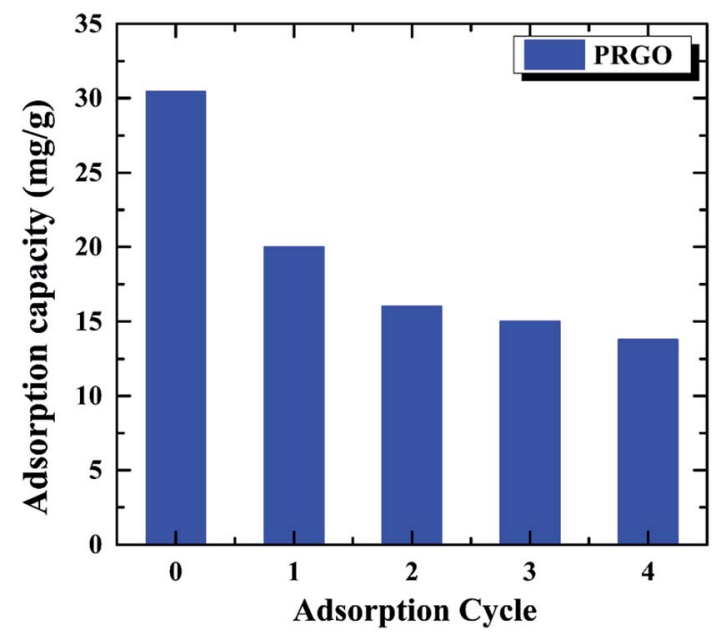

Fig. 6 Recycling of PRGO on the removal of Oll dye. The initial OII

\begin{tabular}{|c|c|c|c|c|c|}
\hline \multirow[t]{3}{*}{ Langmuir } & $q_{\max }\left(\mathrm{mg} \mathrm{g}^{-1}\right)$ & 8.36 & 16.7 & 22.6 & 32.2 \\
\hline & $k_{\mathrm{L}}\left(\mathrm{L} \mathrm{mg}^{-1}\right)$ & $7.4 \times 10^{-2}$ & $1.2 \times 10^{-1}$ & $1.4 \times 10^{-1}$ & $2.3 \times 10^{-1}$ \\
\hline & $R^{2}$ & 0.970 & 0.979 & 0.969 & 0.985 \\
\hline \multirow[t]{2}{*}{ Freundlich } & $1 / n$ & 0.445 & 0.337 & 0.325 & 0.243 \\
\hline & $K_{\mathrm{F}}\left(\mathrm{L} \mathrm{mg}^{-1}\right)$ & 1.24 & 4.07 & 5.94 & 13.0 \\
\hline & $K_{\mathrm{T}}\left(\mathrm{L} \mathrm{mg}^{-1}\right)$ & 0.677 & 1.81 & 2.55 & 4.19 \\
\hline & $R^{2}$ & 0.923 & 0.944 & 0.931 & 0.969 \\
\hline
\end{tabular}
concentration was $60 \mathrm{mg} \mathrm{L}^{-1}$.

Table 3 Parameters of the Langmuir, Freundlich and Temkin models 


$$
\theta=\frac{R T}{\Delta Q} \ln C_{\mathrm{e}}+\frac{R T}{\Delta Q} \ln K_{\mathrm{T}}
$$

where $\theta=q_{\mathrm{e}} / q_{\mathrm{max}}$, is the fraction coverage. $R$ is the universal gas constant and equals to $8.314 \mathrm{~J}\left(\mathrm{~mol}^{-1} \mathrm{~K}^{-1}\right), T$ is the temperature and equals to $295 \mathrm{~K}\left(22^{\circ} \mathrm{C}\right)$ in the experiments. $\Delta Q$ is the vitiation of adsorption energy in $\mathrm{J} \mathrm{mol}^{-1}$ and $K_{\mathrm{T}}$ is the Temkin equilibrium constant in $\mathrm{L} \mathrm{mg}^{-1}$. The Temkin parameters have been determined by linearly fitting the plots of $q_{\mathrm{e}} / q_{\max }$ against $\ln C_{\mathrm{e}}$, as shown in Fig. $5 \mathrm{~d}$, and the results have been presented

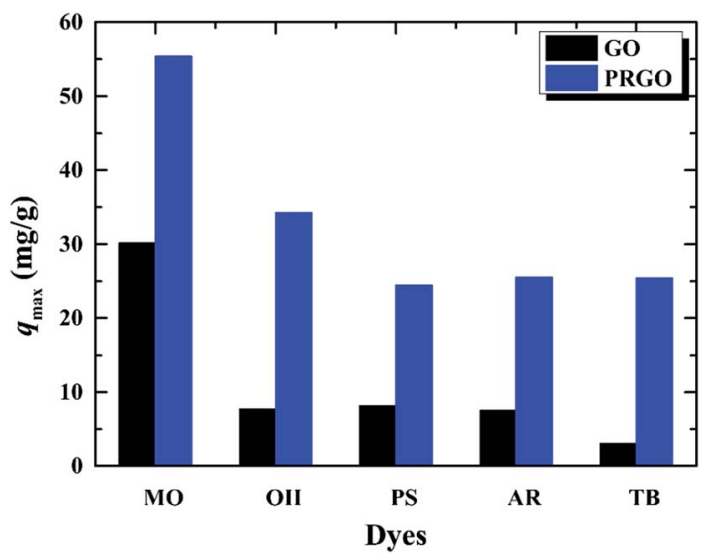

Fig. 7 Adsorption capacities of five anionic dyes on GO and PRGO with irradiation time of $72 \mathrm{~h}$, respectively. in Table 3. The applicable $R^{2}$ illustrate the isotherm data can be fitted with the Temkin model. The values of $\Delta Q$ are all positive, suggesting that the adsorption reaction is exothermic in nature. $^{42}$ Therefore high temperature is not favorable for anionic dye adsorption. Both $\Delta Q$ and $K_{\mathrm{T}}$ increase with the reduction degree, revealing that the adsorption is more favorable for the PRGO materials.

\subsection{Desorption and recycle of PRGO}

The recycling and regenerating ability of an adsorbent is crucial for its practical application, an excellent adsorbent not only has the high adsorption capacity, but also can be recycling to save energy. In order to investigate the recycling ability of PRGO as the adsorbent, the OII solution with the initial concentration of $60 \mathrm{mg} \mathrm{L}{ }^{-1}$ was used to study the adsorption-desorption cycle experiment for five times. After the OII adsorbed on PRGO, it was washed by EG and deionized water for three times, respectively. The recycled adsorbed behavior are shown in Fig. 6. It can be found that the adsorption capacity of $30.4 \mathrm{mg} \mathrm{g}^{-1}$ for the initial adsorption decreases to $13.8 \mathrm{mg} \mathrm{g}^{-1}$ after four cycles, without considering the loss of PRGO materials during the cycling. Although the adsorption decrease rapidly, it is tending towards stability and keeping at $\sim 13.5 \mathrm{mg} \mathrm{g}^{-1}$ at last. The rapid decrease during recycling may be attributed to the strong $\pi-\pi$ stacking interaction between the aromatic structure of dye and the $\mathrm{sp}^{2}$ framework of PRGO surface, preventing desorption of dyes from the PRGO during simple washing (a)<smiles>CN(C)c1ccc(/N=N/c2ccc(S(=O)(=O)O[NH3+])cc2)cc1</smiles>

MO

(c)<smiles>O=[N+]([O-])OS(=O)(=O)c1ccc(/N=N/c2ccc(/N=N/c3c(O)ccc4ccccc34)c(S(=O)(=O)O)c2)cc1</smiles>

(b)<smiles>O=S(=O)(O[Na])c1ccc(/N=N/c2c(O)ccc3ccccc23)cc1</smiles>

(d)<smiles></smiles>

(e)

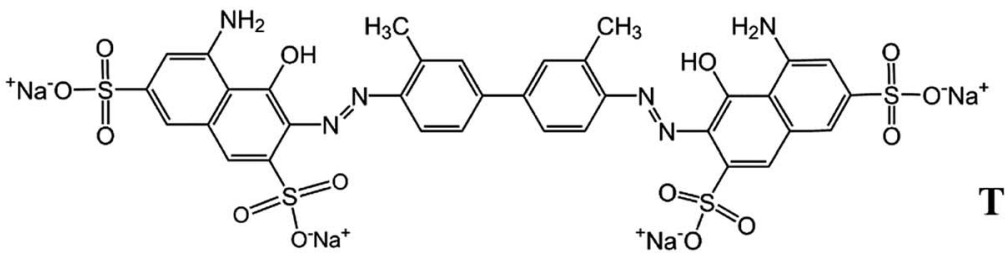

AR

Fig. 8 (a)-(e) are the chemical structures of MO, OII, PS, AR, and TB anionic dyes used in the experiments. 
processes. ${ }^{15,43}$ After the adsorption sites with strong interaction have been saturated by dyes, the adsorption capacity stands at a plateau level. The still adsorption may arise from the adsorption sites with remaining oxygen-containing functional groups surrounding, resulting in the relatively weak adsorption and the facile desorption.

\subsection{Adsorption of other anionic dyes}

In order to verify whether the PRGO can be applied as a broad and efficient adsorbent to remove the anionic dyes with different aromatic structures and negative charges, the adsorption capacities of GO and PRGO have also been measured towards to MO, PS, AR, and TB, respectively, as shown in Fig. 7. Apparently, for all these anionic dyes, the PRGO shows significantly improved adsorption capacities. Among them, TB presents the maximum enhanced folds of $\sim 8$. The reason may be distinguished into two aspects. The TB with four negative charges, as presented in Fig. 8, will emerge the strongest repulsion interaction between $\mathrm{TB}$ and negative GO surface, leading to the weakest absorption capacity on GO. On the other hand, the TB has six aromatic rings, which makes strong $\pi-\pi$ stacking interaction between TB and PRGO surface, resulting in large adsorption capacity on PRGO. The PS and AR with similar chemical structures and negative charges perform almost the same results. The enhanced folds for them are 3 and 3.4, respectively. The repulsion interaction between them and GO, and also the $\pi-\pi$ stacking interaction between them and PRGO are both moderate. In the experiments, MO shows the largest adsorption capacity on GO among dyes, and also the smallest enhanced folds of $\sim 2$. It can be attributed to the weak repulsion interaction between $\mathrm{MO}$ and GO, as well as the relative simple chemical structure makes MO adsorbing on the residual $\mathrm{sp}^{2}$ framework of GO efficiently.

\section{Conclusion}

In this study, a green and cost-free method based on the solar light irradiation was developed to prepare PRGO suspension in order to improve the adsorption capacity on anionic dyes in water treatment. Characterizations by UV-visible absorption, Raman, AFM, SEM, FTIR and XPS proved the successful reduction of GO suspension under solar light irradiation. Three commonly used kinetic models and three isotherm models were applied to reveal the adsorption mechanisms of OII dye adsorbed on GO and PRGO, respectively. The well-fitted pseudosecond order kinetic model as well as simultaneously adopted Langmuir, Freundlich and Temkin models reveal that the adsorption is a monolayer and exothermic process. The maximum adsorption capacities of PRGO for five anionic dyes, MO, OII, PS, AR, and TB are determined, which is much higher than that of the pristine GO, with the enhanced folds of $\sim 2,4,3$, 3.4 , and 8, respectively. The significant improved adsorption is attributed to the decrease of charge density of GO surface by removing the oxygen-containing functional groups, and the increase of $\pi-\pi$ stacking interaction between aromatic dyes and PRGO by restoring the $\mathrm{sp}^{2} \pi$-conjugation frameworks during solar reduction. The enhanced adsorption capacity strong suggests that PRGO reduction by solar irradiation has great potential to be used as a promising adsorbent for the high efficiency removal of anionic dyes in the wastewater treatment.

\section{Conflicts of interest}

The authors declare that no competing financial conflicts exist.

\section{Acknowledgements}

The project is sponsored by the National Key Research and Development Program of China (Grant No. 2017YFA0304203), the Natural Science Foundation of China (Grant No. 11404200, 61527824, 11374196, 61605104 and U1510133), the Program for Changjiang Scholars and Innovative Research Team in University (Grant No. IRT13076).

\section{References}

1 J. Eliasson, Nature, 2015, 517, 6.

2 I. Ali, Chem. Rev., 2012, 112, 5073-5091.

3 M. T. Yagub, T. K. Sen, S. Afroze and H. M. Ang, Adv. Colloid Interface Sci., 2014, 209, 172-184.

4 H. Sun, L. Cao and L. Lu, Nano Res., 2011, 4, 550-562.

5 M. R. S. Kebria, M. Jahanshahi and A. Rahimpour, Desalination, 2015, 367, 255-264.

6 J. Labanda, J. Sabaté and J. Llorens, J. Membr. Sci., 2009, 340, 234-240.

7 G. C. Silva, V. S. T. Ciminelli, A. M. Ferreira, N. C. Pissolati, P. R. P. Paiva and J. L. López, Mater. Res. Bull., 2014, 49, 544-551.

8 C. Li, H. Zhu, X. She, T. Wang, F. She and L. Kong, RSC Adv., 2016, 6, 67242-67251.

9 K. S. Novoselov, V. I. Fal'ko, L. Colombo, P. R. Gellert, M. G. Schwab and K. Kim, Nature, 2012, 490, 192-200.

10 C. Lee, X. Wei, J. W. Kysar and J. Hone, Science, 2008, 321, 385-388.

11 R. K. Upadhyay, N. Soin and S. S. Roy, RSC Adv., 2014, 4, 3823-3851.

12 S. Chowdhury and R. Balasubramanian, Adv. Colloid Interface Sci., 2014, 204, 35-56.

13 J.-H. Deng, X.-R. Zhang, G.-M. Zeng, J.-L. Gong, Q.-Y. Niu and J. Liang, Chem. Eng. J., 2013, 226, 189-200.

14 G. Z. Kyzas, E. A. Deliyanni and K. A. Matis, J. Chem. Technol. Biotechnol., 2014, 89, 196-205.

15 J. Wang and B. Chen, Chem. Eng. J., 2015, 281, 379-388.

16 X. Wang, S. Huang, L. Zhu, X. Tian, S. Li and H. Tang, Carbon, 2014, 69, 101-112.

17 G. K. Ramesha, A. V. Kumara, H. B. Muralidhara and S. Sampath, J. Colloid Interface Sci., 2011, 361, 270-277.

18 L. Sun, H. Yu and B. Fugetsu, J. Hazard. Mater., 2012, 203204, 101-110.

19 J. Xiao, W. Lv, Z. Xie, Y. Tan, Y. Song and Q. Zheng, J. Mater. Chem. A, 2016, 4, 12126-12135.

$20 \mathrm{~V}$. Eswaraiah, S. S. Jyothirmayee Aravind and S. Ramaprabhu, J. Mater. Chem., 2011, 21, 6800. 
21 M. Mohandoss, S. S. Gupta, A. Nelleri, T. Pradeep and S. M. Maliyekkal, RSC Adv., 2017, 7, 957-963.

22 W. He, C. Qin, Z. Qiao, G. Zhang, L. Xiao and S. Jia, Carbon, 2016, 109, 264-268.

23 Z. Qiao, C. Qin, Y. Gao, G. Zhang, R. Chen, L. Xiao and S. Jia, Sci. Rep., 2015, 5, 14441.

24 H. T. Zhou, C. B. Qin, R. Y. Chen, G. F. Zhang, L. T. Xiao and S. T. Jia, Appl. Phys. Lett., 2014, 105, 153301.

25 R. Y. N. Gengler, D. S. Badali, D. Zhang, K. Dimos, K. Spyrou, D. Gournis and R. J. D. Miller, Nat. Commun., 2013, 4, 2560. 26 A. Kaniyoor and S. Ramaprabhu, AIP Adv., 2012, 2, 032183. 27 S. Stankovich, D. A. Dikin, R. D. Piner, K. A. Kohlhaas, A. Kleinhammes, Y. Jia, Y. Wu, S. T. Nguyen and R. S. Ruoff, Carbon, 2007, 45, 1558-1565.

28 F. Tuinstra and J. L. Koenig, J. Chem. Phys., 1970, 53, 11261130.

29 J. Chen, B. Yao, C. Li and G. Shi, Carbon, 2013, 64, 225-229. 30 H. Feng, R. Cheng, X. Zhao, X. Duan and J. Li, Nat. Commun., 2013, 4, 1539.

31 V. Le Borgne, H. Bazi, T. Hayashi, Y. A. Kim, M. Endo and M. A. El Khakani, Carbon, 2014, 77, 857-867.

32 Y. Matsumoto, M. Koinuma, S. Ida, S. Hayami, T. Taniguchi, K. Hatakeyama, H. Tateishi, Y. Watanabe and S. Amano, J. Phys. Chem. C, 2011, 115, 19280-19286.
33 Q. Zhang, H. Zheng, Z. Geng, S. Jiang, J. Ge, K. Fan, S. Duan, Y. Chen, X. Wang and Y. Luo, J. Am. Chem. Soc., 2013, 135, 12468-12474.

34 J. N. Tiwari, K. Mahesh, N. H. Le, K. C. Kemp, R. Timilsina, R. N. Tiwari and K. S. Kim, Carbon, 2013, 56, 173-182.

35 X. H. Li, J. S. Chen, X. Wang, M. E. Schuster, R. Schlogl and M. Antonietti, ChemSusChem, 2012, 5, 642-646.

36 Y. Matsumoto, M. Koinuma, S. Y. Kim, Y. Watanabe, T. Taniguchi, K. Hatakeyama, H. Tateishi and S. Ida, ACS Appl. Mater. Interfaces, 2010, 2, 3461-3466.

37 M. Acik, G. Lee, C. Mattevi, M. Chhowalla, K. Cho and Y. J. Chabal, Nat. Mater., 2010, 9, 840-845.

38 R. J. W. E. Lahaye, H. K. Jeong, C. Y. Park and Y. H. Lee, Phys. Rev. B, 2009, 79, 125435.

39 Y. Qi, M. Yang, W. Xu, S. He and Y. Men, J. Colloid Interface Sci., 2017, 486, 84-96.

40 X. Mi, G. Huang, W. Xie, W. Wang, Y. Liu and J. Gao, Carbon, 2012, 50, 4856-4864.

41 M. Heidarizad and S. S. Şengör, J. Mol. Liq., 2016, 224, 607617.

42 Y. Wang, Y. Xie, Y. Zhang, S. Tang, C. Guo, J. Wu and R. Lau, Chem. Eng. J., 2016, 114, 258-267.

43 S. Bai, X. Shen, X. Zhong, Y. Liu, G. Zhu, X. Xu and K. Chen, Carbon, 2012, 50, 2337-2346. 